\title{
Awareness of Breast Cancer among Youth: A Case Study of Modibbo Adama University of Technology, Yola - Nigeria
}

\author{
Zubaida Hassan", Shitu A. S. \\ Department of Microbiology, School of Pure and Applied Sciences, Modibbo Adama University of Technology, Yola \\ *Corresponding author: zubaidahassan@mautech.edu.ng
}

\begin{abstract}
Although programmes promoting breast cancer awareness are being carried out in some part of Nigeria, however, few if any, targeted youth especially university students. This study was conducted to assess the knowledge of 100 university youths on breast cancer. The study was carried out using a self-administered questionnaire. The respondents' knowledge regarding risk factors for breast cancer in this sample was poor. Among the study population, there were significant deficiencies in attitudes and practices on breast cancer self-examinations and the knowledge of using biotherapy in cancer treatment. Interestingly, internet and media channels played a significant role in breast cancer awareness. The study concluded that, there is need for more awareness programs aimed specifically at this important target group especially through media sources.
\end{abstract}

Keywords: awareness, breast cancer, youth

Cite This Article: Zubaida Hassan, and Shitu A. S., "Awareness of Breast Cancer among Youth: A Case Study of Modibbo Adama University of Technology, Yola - Nigeria." Journal of Cancer Research and Treatment, vol. 5, no. 2 (2017): 73-76. doi: 10.12691/jcrt-5-2-6.

\section{Introduction}

Cancer awareness is the state of having knowledge of how cancer starts, develops and current research output on its remedy. Breast cancer is one of the leading cancer related deaths [2]. The incidence of breast cancer is rising rapidly and has become the commonest malignancy in the world [1]. This escalation can be attributed to lack of awareness coupled with late diagnosis of the disease $[10,11]$. This calls for emphasis on the need to raise awareness on breast cancer to improve life quality and survival rate due to ever increasing burden of this deadly disease (breast cancer). Availability of breast cancer screening centres is no doubt the main source of awareness of cancer. However, in Adamawa state, such centres are not in practical state. Therefore awareness through University students can go a long way as it can spread among populace of the state and even the Nation at large within a limited time frame. Despite the seeming gloomy outlook, breast cancer should not be a death sentence as there are proven ways to reduce the mortality rate and improve patient diagnosis if detected early through regular breast cancer screening programs [5].

It was reported that, the main reason for rapid increase in the incidence of breast cancer may be attributed to lack of awareness coupled with late diagnosis such that majority of the affected patients present late in the hospital when little or nothing can be done again [10]. Awareness can be done through the establishment of trained breast cancer awareness peer group, the use of internet, broadcast media, social media, as well as the use of posters. According to Dutta [4] broadcast media, social media and internet are best suited for providing awareness particularly if the message features entertainment and education. The prevalence of breast cancer gave it substantially more coverage than other major diseases [7].

From the study of Bisen [3], although cancer has been in existence since probably the trace of civilization; however, it became more pronounced in the $19^{\text {th }}$ century. There could be many reasons for which cancer remained out of public attention especially among the youth. One of such reasons may be linked to lack of awareness. Thus, the objective of this study was to create and access the level of awareness of breast cancer among university youth.

\section{Materials and Methods}

The data collection instrument for this study was a selfadministered questionnaire. Informed verbal consent and written questionnaire were received from all the volunteering students. Privacy and confidentiality of all information obtained was ensured both during and after the study process. Individuals were not identified in any publication or report base on this information. Information obtained was used strictly for the purpose of the research.

Four hundred Level from the department of Microbiology, Modibbo Adama University of Technology (MAUTech.), Yola were used as research assistants during the sample collection exercise so as to reach out to many students. The students developed the questionnaire with the 
supervision of the author. For easy assimilation and response of the subjects, the questionnaire was divided into two parts; General awareness on breast cancer, and Awareness on cancer biotherapy, and the response was based on Yes or No. Participants were drawn from undergraduate students randomly selected from the six schools in the University and the purpose of the study was explained to them. Those who freely agreed to participate were issued the questionnaire. A total of 100 students were enrolled into each section of the study. Data was analysed using IBM SPSS statistics software 21 (USA). Knowledge was scored using percentages and univariate analysis was used for comparisons as adopted from the study of Ranasinghe et al, [13].

\section{Results}

The questionnaire that assessed the knowledge of students on General awareness on breast cancer yielded equal number of males and females ( $50 \%$ each). It is Interesting to note that internet and media channels played major role in the breast cancer awareness. All the respondents (100\%) heard of breast cancer through either media or internet source. General knowledge of MAUTech students on breast cancer is summarised in Table 1 . The univariate analysis that compared gender to other awareness questions (between group effects) revealed that out of the 16 questions assessed, only 4 were significant at $\mathrm{p} \leq 0.05$. Of the most common risk factors of breast cancer mentioned, none was significant (Table 2). This simply means that, on the average, general knowledge of MAUTech students on breast cancer is poor.

The questionnaire that assessed the knowledge of students regarding Awareness on the use of biotherapy in cancer science yielded more of female participants than males (59\% vs $41 \%$ ). It is a well-known fact, that biotherapy is important in cancer treatment, although most of it is still in preclinical stage [9]. However, biotherapy possesses significant anticancer properties at a cheaper and readily affordable cost. From the result (Table 3), it is obvious that most of the students are not aware of biotherapy or its importance in cancer treatment. For example, $71 \%$ of the students answered "Yes" to the question "Have you heard of cancer or its treatments?" but only 52\% of them answered "Yes" to "Is biotherapy good for cancer treatment ?" and only 23\% had a "Yes" answer to "Is biotherapy important in cancer treatment?". For the univariate analysis that compared gender to other awareness questions (between group effects), only the question "Has somebody related to you used biotherapy before" had a significant difference $(F=4.753, p=0.032)$. This showed that, before conducting this study, most of the students, irrespective of gender were not aware of breast cancer risk factors or the use of biotherapy in cancer treatment.

Table 1. General knowledge of MAUTech students on breast cancer

\begin{tabular}{|c|c|c|c|c|c|c|}
\hline $\mathrm{S} / \mathrm{N}$ & Factor & Response & Frequency & Percent & Valid Percent & Cumulative Percent \\
\hline \multirow{2}{*}{1} & \multirow{2}{*}{ Gender } & Male & 50 & 50.0 & 50.0 & 50.0 \\
\hline & & Female & 50 & 50.0 & 50.0 & 100.0 \\
\hline \multirow{2}{*}{2} & \multirow{2}{*}{ Have you ever heard of breast cancer before } & No & 28 & 28.0 & 28.0 & 28.0 \\
\hline & & Yes & 72 & 72.0 & 72.0 & 100.0 \\
\hline \multirow{2}{*}{3} & \multirow{2}{*}{$\begin{array}{l}\text { Are you aware of any signs or symptoms of breast } \\
\text { cancer }\end{array}$} & No & 28 & 28.0 & 28.0 & 28.0 \\
\hline & & Yes & 72 & 72.0 & 72.0 & 100.0 \\
\hline \multirow{2}{*}{4} & \multirow{2}{*}{ Have you heard of breast cancer in men } & No & 78 & 78.0 & 78.0 & 78.0 \\
\hline & & Yes & 22 & 22.0 & 22.0 & 100.0 \\
\hline \multirow{2}{*}{5} & \multirow{2}{*}{$\begin{array}{l}\text { If you heard of breast cancer, was the source of } \\
\text { your awareness from internet or media }\end{array}$} & No & 0 & 0.0 & 0.0 & 0.0 \\
\hline & & Yes & 100 & 100.0 & 100.0 & 100.0 \\
\hline \multirow{2}{*}{6} & \multirow{2}{*}{$\begin{array}{l}\text { Do early stage of cancer detection, diagnosis and } \\
\text { treatment help to cure cancer }\end{array}$} & No & 30 & 30.0 & 30.0 & 30.0 \\
\hline & & Yes & 70 & 70.0 & 70.0 & 100.0 \\
\hline \multirow{2}{*}{7} & \multirow{2}{*}{ Women are more susceptible to breast cancer } & No & 26 & 26.0 & 26.0 & 26.0 \\
\hline & & Yes & 74 & 74.0 & 74.0 & 100.0 \\
\hline 8 & $\begin{array}{l}\text { Do you have good knowledge of breast cancer } \\
\text { self-examination }\end{array}$ & Yes & 62 & 62.0 & 62.0 & 100.0 \\
\hline \multirow{2}{*}{9} & \multirow{2}{*}{$\begin{array}{l}\text { Do u know how to perform breast cancer self- } \\
\text { examination }\end{array}$} & No & 66 & 66.0 & 66.0 & 66.0 \\
\hline & & Yes & 34 & 34.0 & 34.0 & 100.0 \\
\hline \multirow{2}{*}{10} & \multirow{2}{*}{$\begin{array}{l}\text { Can breast cancer self-examination help in early } \\
\text { detection }\end{array}$} & No & 40 & 40.0 & 40.0 & 40.0 \\
\hline & & Yes & 60 & 60.0 & 60.0 & 100.0 \\
\hline \multirow{2}{*}{11} & \multirow{2}{*}{ Have you ever seen someone with breast cancer } & No & 70 & 70.0 & 70.0 & 70.0 \\
\hline & & Yes & 30 & 30.0 & 30.0 & 100.0 \\
\hline \multirow{2}{*}{12} & \multirow{2}{*}{ Are you aware of any breast cancer risk factor } & No & 32 & 32.0 & 32.0 & 32.0 \\
\hline & & Yes & 68 & 68.0 & 68.0 & 100.0 \\
\hline \multirow{2}{*}{13} & \multirow{2}{*}{ Do age contribute to breast cancer risk } & No & 72 & 72.0 & 72.0 & 72.0 \\
\hline & & Yes & 28 & 28.0 & 28.0 & 100.0 \\
\hline \multirow{2}{*}{14} & \multirow{2}{*}{ Do you think breast cancer can be inherited } & No & 76 & 76.0 & 76.0 & 76.0 \\
\hline & & Yes & 24 & 24.0 & 24.0 & 100.0 \\
\hline 15 & Are smoking and alcoholism breast cancer risk & No & 48 & 48.0 & 48.0 & 48.0 \\
\hline 15 & factors & Yes & 52 & 52.0 & 52.0 & 100.0 \\
\hline & Is exposure to carcinogenic products breast cancer & No & 46 & 46.0 & 46.0 & 46.0 \\
\hline 16 & risk factors & Yes & 54 & 54.0 & 54.0 & 100.0 \\
\hline & Fating hich fat diot is a broact concer rick foctor & No & 70 & 70.0 & 70.0 & 70.0 \\
\hline 17 & Eating high fat diet is a breast cancer risk factor & Yes & 30 & 30.0 & 30.0 & 100.0 \\
\hline
\end{tabular}


Table 2. Tests of Between-Subjects Effects

\begin{tabular}{|c|c|c|c|c|c|}
\hline \multicolumn{6}{|c|}{ Dependent Variable: gender } \\
\hline Source & Type III Sum of Squares & df & Mean Square & $\mathrm{F}$ & Sig. \\
\hline Corrected Model & $6.218^{\mathrm{a}}$ & 15 & .415 & 1.854 & .040 \\
\hline Intercept & 6.781 & 1 & 6.781 & 30.327 & .000 \\
\hline Have you ever heard of breast cancer before & 1.144 & 1 & 1.144 & 5.118 & .026 \\
\hline Women are more susceptible to breast cancer & 1.003 & 1 & 1.003 & 4.484 & .037 \\
\hline Are you aware of any breast cancer risk factor & 1.597 & 1 & 1.597 & 7.142 & .009 \\
\hline Is exposure to carcinogenic products breast cancer risk factors & .787 & 1 & .787 & 3.521 & .064 \\
\hline Error & 18.782 & 84 & .224 & & \\
\hline Total & 50.000 & 100 & & & \\
\hline Corrected Total & 25.000 & 99 & & & \\
\hline
\end{tabular}

Table 3. Awareness of MAUTech students on cancer biotherapy

\begin{tabular}{|c|c|c|c|c|c|c|}
\hline $\mathrm{S} / \mathrm{N}$ & Factor & Response & Frequency & Percent & Valid Percent & Cumulative Percent \\
\hline \multirow{2}{*}{1} & \multirow{2}{*}{ Gender } & Male & 41 & 41.0 & 41.0 & 41.0 \\
\hline & & Female & 59 & 59.0 & 59.0 & 100.0 \\
\hline \multirow{2}{*}{2} & \multirow{2}{*}{ Have you heard of cancer or its treatments } & No & 29 & 29.0 & 29.0 & 29.0 \\
\hline & & Yes & 71 & 71.0 & 71.0 & 100.0 \\
\hline \multirow{2}{*}{3} & \multirow{2}{*}{$\begin{array}{l}\text { Have you being with a cancer patient treated } \\
\text { using biotherapy }\end{array}$} & No & 55 & 55.0 & 55.0 & 55.0 \\
\hline & & Yes & 45 & 45.0 & 45.0 & 100.0 \\
\hline \multirow{2}{*}{4} & \multirow{2}{*}{$\begin{array}{l}\text { Is biotherapy a means of cancer treatment in } \\
\text { your locality }\end{array}$} & No & 24 & 24.0 & 24.0 & 24.0 \\
\hline & & Yes & 76 & 76.0 & 76.0 & 100.0 \\
\hline \multirow{2}{*}{5} & \multirow{2}{*}{$\begin{array}{l}\text { Has somebody related to you used biotherapy } \\
\text { before }\end{array}$} & No & 53 & 53.0 & 53.0 & 53.0 \\
\hline & & Yes & 47 & 47.0 & 47.0 & 100.0 \\
\hline \multirow{2}{*}{6} & \multirow{2}{*}{ Is biotherapy dangerous } & No & 31 & 31.0 & 31.0 & 31.0 \\
\hline & & Yes & 69 & 69.0 & 69.0 & 100.0 \\
\hline \multirow{2}{*}{7} & \multirow{2}{*}{$\begin{array}{l}\text { Have you ever attended seminar, lecture or any } \\
\text { form of cancer awareness }\end{array}$} & No & 51 & 51.0 & 51.0 & 51.0 \\
\hline & & Yes & 49 & 49.0 & 49.0 & 100.0 \\
\hline \multirow{2}{*}{8} & \multirow{2}{*}{ Is biotherapy good for cancer treatment } & No & 48 & 48.0 & 48.0 & 48.0 \\
\hline & & Yes & 52 & 52.0 & 52.0 & 100.0 \\
\hline \multirow{2}{*}{9} & \multirow{2}{*}{ Have you meet an oncologist before } & No & 49 & 49.0 & 49.0 & 49.0 \\
\hline & & Yes & 51 & 51.0 & 51.0 & 100.0 \\
\hline \multirow{2}{*}{10} & \multirow{2}{*}{$\begin{array}{l}\text { Incase if you or anyone develops cancer, will } \\
\text { you recommend biotherapy }\end{array}$} & No & 63 & 63.0 & 63.0 & 63.0 \\
\hline & & Yes & 37 & 37.0 & 37.0 & 100.0 \\
\hline \multirow{2}{*}{11} & \multirow{2}{*}{ Have you done cancer check-up before } & No & 71 & 71.0 & 71.0 & 71.0 \\
\hline & & Yes & 29 & 29.0 & 29.0 & 100.0 \\
\hline \multirow{2}{*}{12} & \multirow{2}{*}{ Would you mind ban of biotherapy } & No & 46 & 46.0 & 46.0 & 46.0 \\
\hline & & Yes & 54 & 54.0 & 54.0 & 100.0 \\
\hline \multirow{2}{*}{13} & \multirow{2}{*}{$\begin{array}{l}\text { Have you used biotherapy in treatment of other } \\
\text { diseases }\end{array}$} & No & 61 & 61.0 & 61.0 & 61.0 \\
\hline & & Yes & 39 & 39.0 & 39.0 & 100.0 \\
\hline \multirow{2}{*}{14} & \multirow{2}{*}{$\begin{array}{l}\text { Do you think biotherapy improve cancer } \\
\text { treatment }\end{array}$} & No & 66 & 66.0 & 66.0 & 66.0 \\
\hline & & Yes & 34 & 34.0 & 34.0 & 100.0 \\
\hline & & No & 77 & 77.0 & 77.0 & 77.0 \\
\hline 15 & Is biotherapy beneficial & Yes & 23 & 23.0 & 23.0 & 100.0 \\
\hline 16 & & No & 74 & 74.0 & 74.0 & 74.0 \\
\hline 16 & Is biotherapy important in cancer treatment & Yes & 26 & 26.0 & 26.0 & 100.0 \\
\hline 17 & Is bintherany awaronecs imnortant in the cociotv & No & 73 & 73.0 & 73.0 & 73.0 \\
\hline 17 & Is biotherapy awareness important in the society & Yes & 27 & 27.0 & 27.0 & 100.0 \\
\hline
\end{tabular}

\section{Discussion}

Developing proper health practices should commence as early as possible as it lead to lifetime maintenance of good health. The youths are important target group for promotion of fight against cancer. To my knowledge, there are no published data on the assessment of breast cancer awareness on university students in this area and generally, few of such studies have seen published worldwide [13]. In accordance with the outcome from study of Ranasinghe et al., [13], the knowledge regarding risk factors for breast cancer in this sample was poor. The majority of respondents were not aware that age, diet and life style contributes to breast cancer. This signifies that 
the global fight against cancer needs to be reinforced to achieve its goal. In fact in the present study, only $24 \%$ of the respondents know that breast cancer can be inherited through inherited BRCA 1 BRCA 2 genes.

The knowledge of the subjects on breast cancer therapy is not encouraging as only $26 \%$ of the students responded "Yes" to the question "Is biotherapy important in cancer treatment?” Despite the role probiotic treatment plays in current cancer chemotherapy. Seminars and lectures on breast cancer are vital in public awareness. This can also be seen when $49 \%$ of the students responded that they heard of cancer and biotherapy from either seminars or lectures. This platform seems to be an effective mode of education.

For early detection, screening and diagnosis, breast cancer self-examination (BSE) is important, however, in this study, $62 \%$ of the respondents claimed to have the knowledge of self-examination but only 34\% know how to perform it. The process of imparting knowledge effectively can be hampered by many factors such as lack of understanding by the recipient, cultural beliefs and social pressure barring discussing or exposure of breast to opposite gender. This result is in line with that of Ranasinghe et al., [13] where they reported $17 \%$ of their respondents claimed to know how to perform BSE, but only one third of them had ever attempted it. Similarly, in Ghana [8], Saudi Arabia [6,12] poor knowledge and attitude to BSE were revealed.

Looking at the role played by media in the breast cancer awareness, the best way out of this lack of proper knowledge among youth at the undergraduate level in the University is to employ public health midwives and public health nurses to enlighten them in physical (that is through organising seminars or public lectures) and in the media especially the university communication channel.

University students are on the average more exposed and informed about current happenings among the overall population of youth in the society; therefore, it is reasonable to assume that the results would be similar if not poorer when conducted at the society level. However, this claim has to be confirmed by further studies. Overall, our findings urge the healthcare sector, educationists and other relevant bodies to rethink on strategy of imparting knowledge to youth on breast cancer awareness. Although, the expected prevalence of breast cancer in adolescent girls is low, targeting such age in health education has far reaching implications.

\section{Conclusion}

This study provides important baseline information regarding the knowledge on breast cancer, its risk factors and treatments. In MAUTech Yola, the overall knowledge of these among our target population is poor. It is recommend that health professionals help raise the awareness of this important group, by introducing effective breast health programmes that could help youth develop good health habits early on.

\section{Acknowledgements}

All thanks to students of 400 Level (2016/2017 session) of the department of Microbiology, Modibbo Adama University of Technology (MAUTech.), Yola.

\section{References}

[1] Adebamawo, G. A., \& Adekunle, O. O. (1999). Case controlled study of the epidemiology risk factors for breast cancer in Nigeria. British Journal of Surgery, 86, 665-668.

[2] Al Moundhrl, A. L., Al Bahrani, B., \& Pervez, L. (2004). No Title. The Outcome of Treatment of Breast Cancer in a Developing Country, 13(2), 139-142.

[3] Bisen, P. S. (2013). Cancer therapy: An overview. Journal of Cancer Science and Therapy, 6(1), 1000e130.

[4] Dutta, C. (2004). Empowering women for the challenges living against breast cancer. South Korea.

[5] Elmore, J. G., Armstrong, K., Lehman, C. D., \& Fletcher, S. W. (2005). Screening for breast cancer. Journal of the American Medical Association, 1-10.

[6] Hussein, D. M., Alorf, S. H., Al-Sogaih, Y. S., Alaskar, R. S., AlMahana, A. M., Alsalhowb, W. F., ... Hindawi, S. I. (2013). Breast cancer awareness and breast self-examination in Northern Saudi Arabia. A preliminary survey. Saudi Med J., 13, 681-688.

[7] Kitzinger, J. (2000). The role of the media in public and professional understanding of breast cancer. Report for the NHIS, 169-190.

[8] Mena, M., Wiafe Addai, B., Sauvaget, C., Ali, I. A., Wiafe, S. A., Dabis, F., ... Sasco, A. J. (2004). Evaluation of the impact of a breast cancer awareness program in rural Ghana: a cross-sectional survey. Int J Cancer, 913-924.

[9] Nami, Y., Abdullah, N., Haghshenas, B., Radiah, D., Rosli, R., \& Khosroushahi, A. Y. (2014). A newly isolated probiotic Enterococcus faecalis strain from vagina microbiota enhances apoptosis of human cancer cells. Journal of Applied Microbiology, 117, 498-508.

[10] Parkin, D. M., Muic, C. S., Whelan, S. L., Gao, Y., Ferlay, J., \& Powell, J. (1992). Cancer incidence in five continent. IADC Scientific, 6, 120-124.

[11] Pinotti, J. A., Barros, A. C., Hegg, R., \& Zeferino, L. C. (1995). Breast cancer program indeveloping countries. Breast Diseases, 8 , 243-250.

[12] Radi, S. M. (2013). Breast cancer awareness among Saudi females in Jeddah. Asian Pac J Cancer Prev., 13, 4307-4312.

[13] Ranasinghe, H. M., Ranasinghe, N., Rodrigo, C., Seneviratne, R. D. A., \& Rajapakse, S. (2013). Awareness of breast cancer among adolescent girls in Colombo, Sri Lanka: a school based study. BMC Public Health, 13(1), 1209. 